\title{
The Curricular Indian Agent: Discursive Colonization and Indigenous (Dys)Agency in U.S. History Textbooks
}

\section{Author: Christine Rogers Stanton}

This is the peer reviewed version of an article, which has been published in final form at http:// dx.doi.org/10.1111/curi.12064. This article may be used for non-commercial purposes in accordance With Wiley Terms and Conditions for self-archiving.

Stanton, Christine Rogers. "The Curricular Indian Agent: Discursive Colonization and Indigenous (Dys)Agency in U.S. History Textbooks." Curriculum Inquiry 44, no. 5 (December 2014): 649-676. doi $10.1111 /$ curi.12064.

Made available through Montana State University's $\underline{\text { ScholarWorks }}$ 


\title{
Running head: THE CURRICULAR INDIAN AGENT
}

\author{
The Curricular Indian Agent: \\ Discursive Colonization and Indigenous (Dys)Agency in U.S. History Textbooks \\ Accepted for publication with Curriculum Inquiry
}

\author{
Christine Rogers Stanton \\ Montana State University
}

Correspondence concerning this paper should be addressed to Christine Rogers Stanton, Department of Education, Montana State University, Bozeman, MT 59717. Email:

christine.rogers1@montana.edu 


\begin{abstract}
The Curricular Indian Agent: Discursive Colonization and Indigenous (Dys)Agency in U.S. History Textbooks

In the 1800s and early 1900s, the United States assigned Indian Agents - non-Native employees of the federal government - to coordinate intergovernmental efforts, to encourage the assimilation of Native peoples into European American society, and to serve as advocates for individual tribes. Although Indian Agents no longer exist in an official capacity in the U.S., the potentially contradictory expectations that informed their work continue to influence communities across the country. Instead of decolonizing education, today's curricular agents typically misrepresent the historical and future agency of Native peoples while reinforcing the patronizing, normative, dominant culture narrative. This article outlines the critical discourse analysis of five widely adopted U.S. history textbooks, as situated within the broader scope of textbook research and emerging educational movements. Findings show that textbook authors and other curricular agents use strategies of exclusion and passivation to control the historical and curricular agency of Indigenous peoples. Given the influence of educational reform efforts such as those related to the Common Core Standards, now is the critical time to re-theorize curriculum design and inquiry as dialogic, dynamic, transformational, and agentive processes. The project's conclusions demonstrate the need to confront the biases of curricular agents in order to guide the decolonization of curriculum materials.
\end{abstract}




\section{The Curricular Indian Agent:}

\section{Discursive Colonization and Indigenous (Dys)Agency in U.S. History Textbooks}

Of course the primary requisite in such a task as that of Indian Agent is a combination of courteous consideration and firm direction which can only be the issue of intelligent character.

(Alexander, 1926, p. 647)

This introductory quote, which heralds from a 1926 edition of The Nation, demonstrates the dueling qualities that defined the role of Indian Agents in the United States and Canada throughout the 1800 s and into the early $20^{\text {th }}$ Century. Such Agents were appointed to provide supervision of and, in some cases, advocacy for Indigenous peoples under the care and influence of the federal "Great Father" (Prucha, 1986, p. x). Simultaneously, Agents were to serve as government "fieldworkers" assigned to implement federal policies on local levels (Schreiber, 2008, p. 109).

Although the official role of Indian Agent no longer exists, the "double orientation—inward toward native people and outward toward settler society" (Schreiber, 2008, p. 97) inherent to the Indian Agent position remains a powerful force in today's tribal communities, institutions, and schools. Policymakers, curriculum developers, and testing corporations often send an assimilative message to teachers, parents, and tribal community members: To advance opportunities for Indigenous youth, educators must prioritize the knowledge, skills, and ways of thinking valued by the dominant culture. As a result, teachers and tribal community members may find themselves advocating for a curriculum that is actually devoid of Native cultures ${ }^{\mathrm{i}}$. 
It is important to note, however, that, like Indian Agents, curricular agents have the potential to either fortify dominant-culture power (Brayboy, 2005; Said, 1993; Smith, 1999) or to advance the goals of social justice (Sleeter \& Grant, 2009). Specifically, curricular discourse can offer "authority, validations, and legitimization" (Cary \& Matua, 2010, p. 62). In addition, initiatives that emphasize "culturally responsive teaching" (e.g. Gay, 2004), use cultural studies mandates to shape curriculum and pedagogy (e.g. Montana's Indian Education for All), or shift national-level curricular discourse to be more inclusive of tribal experiences (e.g. the C3 Framework for Social Studies State Standards) provide new opportunities to consider issues related to curricular agency. While previous scholarship has noted that curriculum resources frequently ignore, misrepresent, or degrade Native cultural experience and ways of knowing (Costo \& Henry, 1970; Levstik \& Barton, 2010; Loewen, 1995, 2010; Manitoba Indian Brotherhood, 1974; McCoy, 2004; Sanchez, 2007; Stenhouse, 2009), little attention has been given to the potential for such resources, and for the curricular agents who shape them, to actively advance or constrain the "agency" of Indigenous peoples. Additionally, previous work has not directly considered the influence of shifting curricular policy on textbook design and redesign.

The purpose of this article is to explore ways that curricular agents - in particular textbook authors, editors, and publishers - preserve the "double orientation" Indian Agent legacy by investigating how curricular discourse frames the historical participation of Native peoples. In addition, the project considers how the curricular agents represent the contemporary involvement of Native peoples within the design of materials like today's textbooks. This work weaves critical Indigenous theory with discourse analysis 
methodology to consider two questions: (a) How do discursive representations contribute to or challenge concepts of Indigenous historical and curricular (dys)agency? and (b) How might today's curricular agents reshape textbooks to serve as vehicles for decolonization of the curriculum?

While similarities exist among and between Indigenous communities around the world, and while in many ways schooling practices occupy common curricular and pedagogical space regardless of geography, this article focuses on U.S. curricular discourse for several reasons. First, that focus allows an opportunity to situate the research and discussion within a context informed by multiple previous studies, which is important when considering the influence of systemic change on curriculum. Second, it allows analysis of historical events specific to one region, instead of inappropriately claiming generalizations across diverse regions and Indigenous peoples. Third, it provides a timely opportunity to consider the potential for action given rapid standardsbased change impacting U.S. schools. Finally, the current polarized political climate in the U.S. offers an opportunity to analyze curricular decision-making in terms of conscious, subconscious, and dysconscious racism.

\section{Agency \& Dysagency in Curriculum}

In this article, "agent" refers to individuals (e.g. Indian Agents and curricular agents) who make decisions related to dominant culture interests within cross-cultural contexts. While Indian Agents filled official roles as intermediaries between federal government and tribal groups, curricular agents are — in most cases_-not charged specifically with cross-cultural goals. Although such a role is not explicitly noted, 
curricular agents frequently make culturally, economically, and politically motivated decisions.

"Agency" refers to the power of individuals and entities - including the aforementioned agents - to advance their unique agendas. Agency extends beyond the conceptual: It is both “imaginative" (den Heyer \& Abbott, 2011, p. 616) and constructed through discourse and action (Applebaum, 2004). "Historical agency," as defined by den Heyer (2003), refers to the "transpersonal capacity expressed in struggles by social groups over the symbols, images, ideas, and terms through which personal and public relationships become coherent" (p. 430). Such an understanding is complex, since it draws upon a consciousness of potentially conflicting and divergent histories as they inform both "present and future courses of action" (den Heyer \& Abbott, 2011, p. 615). As Applebaum (2004) notes, within social justice contexts "agency" is not only a matter of self-determination or choice for historically oppressed peoples; it also demands attention to the "moral agency of those privileged by hegemonic systems" given its need for social and political consciousness-building, resistance, questioning, and reflexivity (Applebaum, 2004, p. 68).

For the purposes of this article, "curricular agency" refers to the control individuals and entities have over the creation and use of curricular materials. As illustrated by relationships with Indian Agents, Native peoples and government theoretically shared “agency”. In reality, though, Indigenous agency was forcibly contained and constrained by policies that focused on relocation, assimilation, and cultural termination. Similarly, curriculum designers have claimed shared agency by suggesting Native peoples were consulted as reviewers or contributors, although even in 
these cases Native peoples have had limited input into the process of curriculum development and implementation. This "violence of exclusion" results in curricular decision-making that can be "destabilizing" (Applebaum, 2004, p. 65) in terms of agency.

People in power typically assert their agency either by this direct exclusion of the Other, or by controlling the way the agency of the Other is framed. As Kovach (2013) notes, a "lack of understanding within majority culture is indicative of an educational system that has responded to Indigenous experience with: a) active suppression or b) chronic apathy" (p. 113). While the study described in this article demonstrates the prevalence of exclusion and what van Leeuwen (2008) calls "passivation" — or the act of representing social actors as passively "undergoing" an event (p. 33)—specifically within textbook discourse, the broader implications are much more extensive.

Multicultural education theorists have used the prefix "dys-" to emphasize the moral implications of the dominant culture agent's actions or inactions. King (1991) distinguishes between conscious, subconscious, and "dysconscious" racism. In contrast to conscious racism, which is intentional and overt, and subconscious racism, which is subtle and implicit, dysconscious racism results from "an uncritical habit of mind (including perceptions, attitudes, assumptions, and beliefs) that justifies inequity and exploitation by accepting the existing order of things as given" (King, 1991, p. 135). In King's work, the use of "dys-" emphasizes a purposeful resistance to social justice work. Furthermore, it demonstrates the way individuals draw upon external influences to justify that resistance.

In this article, “dysagency” describes curricular agents' uncritical exclusion or passivation of Indigenous agency. In addition to suggesting a counter-form of agency (as 
“dis-” would), “dys-” means “abnormal” or "bad" ("Dys-", n.d.). In other words, the prefix "dys-" notes a corruption of the root word ("agency"). A corruption of agency can result from the influence of colonizing entities, such as the federal government or other dominant culture interests.

\section{Post-Colonial Theory \& Decolonizing Curriculum}

Although post-colonial theory has provided a common ground for global discussions related to power, discourse, and Indigeneity (Ngugi, 1986; Said, 1993), decolonizing scholars argue that the use of "post" is problematic given the continued influence of assimilative, de-culturizing policies. To illustrate this, Aboriginal activist Bobbi Sykes asks: "What? Post-colonialism? Have they left?" (as cited in Smith, 1999, p. 24). In some ways, post-colonial theory fails to fully recognize the historical and ongoing realities of Indigenous peoples. These complex realities were/are not exclusively Indigenous or assimilated - they were/are dynamic, hybridized, and/or emerging.

The role of the Indian Agent was influenced by similar complexities. He was expected to work to resolve "conflicts between the state as protector and the state as assimilative force" (Schreiber, 2008, p. 97). The current educational situation in the U.S. mirrors the Indian Agent era in many ways, including use of geographic isolation, economic oppression, and educational policy to sustain assimilative agendas while simultaneously claiming to expand opportunities (i.e. "close the achievement gap") for Native students. Indigenous communities have not been, and are not, free to make decisions regarding public schooling, given that resistance to broad standards-based curricular reform often results in disqualification for federal or state funding. 
While a post-colonial curriculum developed by and used exclusively within Indigenous communities asserts Indigenous agency and protects specific tribal knowledge, it does not necessarily confront and change the underlying motivations that drive dominant culture economics and policies. To further complicate the issues, Native peoples often have varied, and potentially conflicting, views of agency. For example, some individuals may advocate for instruction only in traditional content and using Native language. Others may encourage a hybrid that revitalizes Indigenous culture and language while also teaching mainstream content and Standard English. Still others may emphasize the importance of economic security for cultural sustainability, and they may encourage schooling that focuses only on the skills and content needed for dominant culture social and economic mobility.

Given the role of "moral agency" within social justice efforts (Applebaum, 2004, p. 68), it is also important to consider curricular decision-making in schools that serve predominantly non-Native students. In these cases, a decolonizing curriculum-a curriculum that deconstructs the colonizing narrative and historical representation of Native peoples - may help teachers and students develop the critical habit of mind needed to effectively advocate for widespread change. To advance decolonization, Tuck and Fine (2007) encourage both Native and non-Native peoples to engage in the active deconstruction of dominant culture narratives while simultaneously advancing community values and Indigenous agency (p. 153).

\section{The Dysconscious Great Father: The Colonizing Legacy of Curricular Agents}

Arguably, not every Indian Agent embarked on his appointment with a goal to eliminate all forms of Indigenous agency. Some demonstrated a basic desire to preserve 
Native ways of life: They endeavored to minimize loss of life and property for both Native and non-Native communities, they worked to diffuse military confrontations, and they supervised distribution of food and supplies. Some Indian Agents recognized the role of culture and epistemology as connected to Indigenous agency by supporting culturally aligned forms of economic development (Kuhlberg, 2011). Others worked to discourage federal officials from forcing Native children to attend assimilative boarding schools (Ostler, 2004). In a few cases, Agents demonstrated interest in cultural practices by visiting ceremonial sites, although such "interest" was justly viewed with a degree of suspicion by Native peoples (Ostler, 2004).

In reality, governmental and agent-enacted paternalism was less often about the care of Indigenous peoples, and more often about preservation of personal and dominant culture economic interests. Critical Race Theorists refer to this as "interest convergence," which emphasizes the tendency for members of the dominant culture to support social justice efforts only if those efforts support dominant culture self-interests (Bell, 1980; Castagno \& Lee, 2007). Milner (2008) clarifies by noting that social justice "will be pursued and advanced when [racial equality and equity] converge with the interests, needs, expectations, and ideologies of Whites" (p. 333).

This concept of interest convergence describes the historical role of the Indian Agent well. Indian Agents were expected to force assimilation of Native peoples into the Eurocentric mainstream society, or, at a minimum, to keep their Native charges from impeding the economic progress of that mainstream society. As a result, Agents directly or indirectly supervised the cultural genocide that encompassed the prohibition of ceremonies, traditional learning, migration, inter-tribal gatherings, and other vital cultural 
practices (Barsh, 2000; Deloria, 1969/1988). In addition to cultural offences, Indian Agents committed acts of economic mismanagement, fraud, bribery, coercion, and abuse (Berger, 2013; Ostler, 2004; Peacock, 2013; Prucha, 1986).

Similarly, an economics-heavy dominant culture narrative has long driven the design of curriculum materials (Apple \& Christian-Smith, 1991; Loewen, 2010; Scott, 2008). In particular, textbook authors, editors, and publishers have provided narrow descriptions of Native peoples and limited support for the advancement of critical pedagogy, since complex and critical accounts question the motivations and actions of the government, Europeans, and Euro-Americans (Sanchez, 2007). Throughout at least the past four decades, portrayals of Native peoples in U.S. history textbooks have reinforced the "existing order of things as given" (Deloria, 1969/1988; Fixico, 1997; Loewen, 1995, 2010). In particular, curricular agents have represented Native peoples in stereotypical, disempowering, or neutralizing ways. Additionally, curricular agents have recently encountered increased pressure to "close the achievement gap" for students of color. Although the resulting curricular decisions may support social justice goals, curricular agents remain driven by profits and political pressure.

This project seeks to extend the work established by previous studies that have considered the representations of Native peoples in U.S. history textbooks, particularly that of Loewen $(1995,2010)$ and Sanchez (2007), which establishes an interest in close evaluation of U.S. history textbooks over time and across publishers. Given the "warnings posed by Loewen" in 1995 (Sanchez, 2007, p. 316), it is evident that the researchers anticipate improvement in terms of representations of Native peoples over 
time. However, Sanchez (2007) notes that textbooks have not changed as much as would be expected "in this era of heightened multicultural sensitivity" (p. 316).

The previous studies have considered textbook discourse in isolation-not in terms of what it suggests about the dysconscious actions of the curricular agents who shape that discourse. For example, Sanchez (2007) refers to the "textbook's treatment of a culture" (p. 316), as if the textbook — not the textbook's authors, contributors, and publishers directly_makes, or resists, change. When the study authors do acknowledge the role of curricular agents, they often normalize the colonizing actions or inactions of those actors by referencing educational policy, much like Indian Agents who justified their decisions by blaming governmental policy, rather than confronting the underlying motivations that affect curricular decision-making.

\section{Methodology}

The study described in this article differs methodologically from previous studies in several ways. First, it focuses on a smaller sample of contemporary textbooks to allow for depth of analysis as well as breadth. Second, it applies a critical discourse tool to enhance analytical rigor. Third, it extends the critical methodology beyond the data analysis by applying guidelines determined by Indigenous theorists, scholars, and communities to derive implications related to curricular change.

Critical scholarship, especially that which considers discursive choices, can serve to initiate the process of advancing social justice within educational systems (Kincheloe, 2006). In order to interrogate the complexity of curricular representations, such work considers both overt messages (e.g. selection or de-selection of events, use of quotations or images, etc.) as well as the "hidden curriculum" (Apple, 1971). 
Indigenous scholars note the need for Native values to guide discourse analyses (Brayboy, 2005; Grande, 2004; Kovach, 2013; Padgett, 2012). For example, curriculum inquiry should recognize the importance of story-sharing, narrative as experience, collective memory, and power relationships (Archibald, 2008; Bishop, 2008; Brayboy, 2005; Grande, 2004; Smith, 1999). This project draws upon Indigenous values and theory to inform application of van Leeuwen's (2008) tools for critical discourse analysis, with the intent to advance conversations regarding the role of agency within curriculum development and change.

Five recent editions of popular U.S. history textbooks were selected for analysis using the American Textbook Council's (ATC) list of widely adopted U.S. history textbooks. The ATC describes itself as "an independent New York-based research organization ... dedicated to improving the social studies curriculum and civic education in the nation's elementary and high schools" (2011, ATC homepage). To determine the most popular texts used in U.S. classrooms today, the ATC synthesizes publisher website information and adoption data from states and large school districts.

Specifically, this study analyzed Glencoe/McGraw Hill's American Vision (Appleby, Brinkley, Broussard, McPherson, \& Ritchie, 2010), Holt McDougal's American Anthem (Ayers, Schulzinger, de la Teja, \& White, 2009), Prentice Hall/Pearson's Pathways to the Present (Cayton, Perry, Reed, \& Winkler, 2007), Holt McDougal's The Americans (Danzer, Klor de Alva, Krieger, Wilson, \& Woloch, 2012), and Prentice Hall/Pearson's A History of the United States (Boorstin \& Kelley, 2007). For ease of readability, shortened versions of the textbooks titles (i.e. Americans, Anthem, 
A History, Pathways, and Vision) will be used throughout this article, and author and date information will not be included in parenthetical references beyond this paragraph.

During the initial phase of analysis, the textbooks were reviewed holistically using open coding (Fairclough, 1992; Gee, 2005). To narrow the synthesis for this article while preserving comparative potential, markers associated with the period typically referred to as "Westward Expansion" into the Great Plains during the last half of the $19^{\text {th }}$ Century guided focused coding. This set of focus markers was selected for several reasons. First, Westward Expansion is one of the most popular units of study associated with Native peoples. Second, when further narrowed to European/Euro-American migration into and across the Great Plains, this set of markers remains accessible even in classes that begin eleventh grade history with the Civil War. Third, representations of Plains Tribes from this period continue to define broader societal beliefs about Native peoples in general in the U.S. Finally, the authors of each of the five textbooks devoted at least a chapter section to the topic of Westward Expansion into the Great Plains, allowing for consistent and in-depth comparisons.

These focus sections were reviewed using van Leeuwen's (2008) tools for critical discourse analysis of representations of social actors, or "participants of social [and historical] practices" (p. 23). Such work considers the use of language to legitimize (or delegitimize) the actions of participants throughout history. Textbook discourse examples that reinforced or countered the "representational choices" (p. 25) identified through van Leeuwen's "sociosemantic inventory" (p. 23) served as the focal points for both situated and line-by-line analysis. 
Within the context of this study, several of van Leeuwen's tools allow close consideration of ways dominant culture curricular agents continue to assert their power while undermining Indigenous agency. Specifically, van Leeuwen notes that authors may "include or exclude social actors to suit...interests and purposes in relation to the readers" (p. 28). Additionally, van Leeuwen argues that authors can "endow social actors with either active or passive roles" (p. 33).

To consider implications for practice and change, a framework based upon tenets for responsive representations of Native histories was developed. The framework draws upon suggestions shared by critical Indigenous scholars (Archibald, 2008; Bishop, 2008; Brayboy, 2005; Deloria, 1988; Fixico, 1997; Grande, 2004; Kovach, 2013; Padgett, 2012), the Constitution of the National Indian Education Association (2011), and Native community members and educators from several states (see "Implications" below).

Several of the framework contributors have guided my understanding about positionality, agency, and social justice. In many ways, my background reflects that of the typical curricular agent. As a non-Native scholar and educator, I face limitations that arise from my own narrow experience and the decades of European-American norms that have shaped my development, especially in terms of my understanding of history, representation, and epistemology. I also have extensive experience as a teacher, teacher educator, and instructional coach, and these experiences inform my understanding of how various forms of racism continue to influence education. For example, I have repeatedly encountered dysconscious resistance from non-Native teachers, who claim that they do not feel it is their place to teach about Native histories. While this argument seems 
conceptually supportive of Indigenous agency, it also provides an escape route for nonNative educators who are unwilling to learn given their own discomfort.

As a result of my privileged positionality as a White educator and scholar, I have several options regarding my participation in the process of decolonizing curriculum: I can assert my historical privilege by excluding and/or controlling representations of the "Other" in my discourse, scholarship, and teaching; I can work with my Indigenous colleagues to change the "existing order of things as given" (King, 1991, p. 135); or I can remove myself entirely from the process to "leave the Indigenous pedagogy to Indigenous people" (Kovach, 2013, p. 117). During analysis of the data for this project, and throughout application of the framework to the results, I became more aware of the tensions and possibilities inherent within each of these three choices.

\section{Results}

Exclusion of Indigenous Agency. Aside from brief descriptions of life before European and Euro-American invasions, curricular agents present Native histories solely within the context of the dominant culture historical narrative. The authors provide no in-depth discussion of parallel histories and confine Native experiences to interactions with Whites. The Pathways authors introduce the focus section with "American Expansion into the West" (p. 491), which suggests that Native peoples and Americans represent two distinct groups, that the events impacting Native peoples in the Great Plains in the late $19^{\text {th }}$ Century were the result of "expansion" (as opposed to "invasion"), and that progress moved in a "Westward" direction.

Furthermore, in most cases, curricular agents over-emphasize violence (e.g. "battles," "massacres," and "attacks") and lawlessness (e.g. "raids" and "stealing"), while 
almost completely excluding peaceful events, efforts, and perspectives. As a result, nonNative actors are privileged and respected, and their actions - however abhorrent — are justified. For example, the authors of Vision note:

As the number of settlers increased, bands of Native Americans began raiding wagon trains and stealing cattle and horses from ranches. By the summer of 1864 , trade had come to a standstill, dozens of homes had been burned, and an estimated 200 settlers had been killed. The territorial governor, John Evans, ordered the Native Americans to surrender at Fort Lyon... What actually happened at Sand Creek is unclear.

(p. 400)

By initiating discussion of the Sand Creek Massacre — an act of genocide which resulted in the death of over 150 Arapaho and Cheyenne, mostly women, children, and elderly people - through the lens of seemingly unlawful actions of the Native participants, the authors provide additional context to support the White perspective, while excluding and invalidating the Native views of the events leading to the Sand Creek Massacre. For example, the authors exclude information regarding the alcohol-fueled arrogance of Colonel Chivington and his men or earlier efforts of Black Kettle to establish peace. The textbook authors position the White social actors as victims and assign blame to the Native participants. Considering the brutality and injustice of the Sand Creek Massacre itself, which occurred after a peaceful surrender, this positioning is especially problematic.

In several of the other textbooks, the authors separate Native peoples from the rest of the "Americans," thereby excluding Native perspectives from the broader American 
narrative. For example, the authors of $A$ History describe the Great Plains as "a place to avoid," assuming that the reader identifies with White settlers more than the Native actors (p. 385). Vision's authors explain the goals guiding the creation of reservations this way: "Many Americans wanted Native Americans to abandon their traditional culture and religions and live like white Americans" (p. 442). In this example, the authors have selected "Americans" to include non-Native peoples in the U.S. - they clearly are not limiting this term only to White Americans, since they use that particular adjective later in the sentence-while specifically excluding and othering Native Americans.

Across all five texts, curricular agents exclude views that conflict with Eurocentric economic values. In Pathways, the authors introduce settlers through the lens of economic productivity: "Many settlers felt justified in taking Indian land because, in their view, they would make it more productive" (p. 492) and "In 1887, a federal law dismantled the Native American concept of shared land in favor of the principle of private property highly valued by Americans" (p. 496). Even when referring to Native experiences, economic productivity is valued: The authors of $A$ History note, "Thousands of Indians made their living off the land..." (p. 385). In the Americans text, the authors attempt to challenge Eurocentric economic perspectives in vague ways: The settlers "argued that the Native Americans had forfeited their rights to the land because they hadn't settled down to 'improve' it' (p. 409). The use of quotation marks around "improve" signals a weak effort by the authors to draw attention to social constructions related to economic progress.

In addition to privileging Eurocentric economic perspectives, the textbooks exclude other Native political and spiritual views. For example, in Pathways, the authors 
describe the Ghost Dance in simplified and paganistic terms, as "a ritual in which people joined hands and whirled in a circle." The authors of Vision use patronizing discourse: "Defying the orders of the government, the Lakota continued to perform the Ghost Dance" (p. 402). However, not all of the textbook authors frame the Ghost Dance in disempowering or overtly rebellious terms. Anthem's authors, for example, open the section with this passage:

Wovoka, a shaman of the Northern Paiute in Nevada, became know as a healer...In 1889 he had a vision...According to most surviving accounts, the message was that the people should get along and not steal or lie or go to war. (p. 438)

This description lends a more positive light to the Ghost Dance than that in the other textbooks. In addition, the authors' attention to "surviving accounts" suggests an effort to seek multiple perspectives, as a means to more fully understand the events and actors. Unfortunately, in the very next paragraph, the authors refer to the Ghost Dance gatherings as "frenzied dances" (p. 438), thereby impersonalizing and degrading the experience.

Curricular agents also exclude Indigenous social views. For example, the textbook authors rarely describe the role of Native women throughout history, and when they do, they most often present them using weak descriptors. This is true even for descriptions of social groups that held women in high esteem, as did many Plains tribes. For example, the Pathways authors provide a sidebar that focuses on Plains women: Women had gained influence in farming villages... Women in nomadic cultures, however, generally had less influence and wealth... and women of the Sioux and 
Comanche nations followed their husbands and fathers on an endless buffalo hunt. Therefore, women spent their time either preparing for the hunt or drying buffalo meat and tanning buffalo hides.

(p. 259)

In contrast, while the activities are basically the same, women are described as important and even powerful by the authors of The Americans: "The women helped butcher the game and prepared the hides that the men brought back to the camp; young women sometimes chose their own husbands" (p. 409). This perspective is more accurately aligned with the traditional views of many Plains groups.

In several other examples, the textbook authors endeavor to include and value Native beliefs. The authors of Pathways explain that invasion of "sacred lands" (p. 492) became the final straw for some Native peoples. Use of "sacred" as a key adjective demonstrates an attention to a view of land that is more culturally appropriate and distinct from the Eurocentric economic view most commonly emphasized in textbooks. Later in the section, the authors explain, "taking up farming offended the beliefs of many Native Americans" (p. 496). This description recognizes cultural views of land and movement—albeit briefly and without contextualization—within the larger fabric of the historical narrative.

The inclusion of Native primary accounts also demonstrates the potential for more responsive discursive decision-making. The focus section in the Americans opens with an account from Zitkala-Ša, a Dakota girl taken to a boarding school. Although the authors omit information about Zitkala-Ša's political activism as an adult, this example is notable for several reasons: 1) it is the initial contact the reader has with Native histories 
as related to "Culture Clash on the Prairie," 2) it uses Zitkala-Ša's Dakota name, and 3) it positions the story under the heading "One American's Story." The authors of A History also demonstrate an effort to include Native perspectives within the wider understanding of U.S. history when they argue that the "Indian Wars" could be considered "another kind of civil war-between two groups of Americans both trying to make their living off the North American continent" (p. 387), a reference to the status of recognized tribes as sovereign dependent nations.

However, inclusion of Native primary accounts does not necessarily result in the validation of Native perspectives. For example, Anthem's authors refer to Chief Joseph several times as "the leader" of the Nez Perce (p. 442). Through the use of this particular article ("the"), the textbook authors exclude information regarding the complex leadership structure of the Nez Perce, while simultaneously privileging European and Euro-American views of hierarchical leadership. In the case of two of the textbooks, Joseph's speech — a rather lengthy segment in comparison to others included throughout the five textbooks - is the exclusive primary account from a Native perspective. In addition to promoting misunderstandings regarding Joseph's role, the speech-as represented by the textbook authors and editors - is a classic example of assimilationist discourse. It has been appropriated by non-Natives for the purpose of promoting obedience, instead of accurately representing intent, resistance, justice, or sovereignty.

Passivation of Native Roles. Discourse that establishes Native peoples as passive social actors dominates the texts: "the Sioux were beaten" (Americans, p. 412), Native peoples were "forced to flee" (Pathways, p. 493), and "Indians [were] used by the army as scouts" (Pathways, p. 497). When paired with descriptions of both Native and 
non-Native social actors, the passivation of Native peoples is even more evident. In Pathways, the authors describe one of the "Key events in the Indian Wars":

Carson kills or relocates many Apache to reservations in 1862. Clashes drag on until Geronimo's surrender in 1886. Navajo told to surrender in 1863, but before they can, Carson attacks, killing hundreds, destroying homelands. Navajos moved to New Mexico reservation in 1865.

(p. 496)

Even when passive sentence construction is avoided, the authors select deficitoriented nouns ("Struggles of the Plains Indians," Vision, p. 398), weak verbs ("The southern Cheyenne occupied the central plains," Pathways, p. 493), and modifiers that suggest surprise at historically explainable phenomena ("Remarkably, by 1894 perhaps as few as 25 buffalo remained," Anthem, p. 439) to describe events.

Another passivation tactic is to position Native actors within the power structure of the U.S. government (e.g. "The Sioux agree to move to a reservation," Vision, p. 399). To reinforce deficit-orientations, the curricular agents use discourse that explicitly discredits Native contributions. For example, the authors of $A$ History give credit to the U.S. government for the survival of Native peoples, as evidenced by "us" and "them" discourse, despite the work by that same government to exterminate Indigenous cultures, as well as extensive efforts by Native communities to revitalize traditional cultures:

Not until 1934 and the "Indian New Deal" did the United States government policy change. An attempt was made to rebuild the tribes and their tribal culture. The Native American population then grew rapidly. (p. 391) 
At times, the textbook authors describe Native peoples in sub-human ways: "In June 1876, Custer was sent to round up the Indians" (Pathways, p. 495) and "On December 28, 1890, the Seventh Calvary_Custer's old regiment—rounded up about 350 starving and freezing Sioux" (Americans, p. 413). In these examples, Native peoples are equated with livestock, even when juxtaposed with the person who was killed by those same Native peoples. Similarly, Native peoples are also described as animalistic predators: "The Sioux fell on their prey" (Pathways, p. 495). The authors of A History suggest that such responses to the White invasion were biologically predetermined: "The Indians naturally resisted" (p. 387).

Additional examples demonstrate the authors' subconscious or dysconscious efforts to perpetuate patriarchal and dominating social discourse. In Pathways, for instance, the authors describe Native peoples who resist treaty mandates as peoples who "refused to obey" (p. 492). In Vision, the authors note, "Pressuring Native American leaders into signing treaties...did not ensure that chiefs or their followers would abide by them" (p. 400). The authors of A History suggest that—despite many accounts of prophetic visions and discussions among tribal leadership - Native peoples were not as politically savvy as Whites: "Although the Indians did not realize it at the time, these treaties really announced the beginning of the end" (p. 387).

The curricular agents appropriate power from Native social actors most notably during the description of the Battle of Little Bighorn: "This battle...might more accurately have been called the Sioux's Last Stand" (A History, p. 389). In the next sentence, the authors argue that the Battle of Little Big Horn led to a "conquered and leaderless" Sioux people (p. 389). Such discourse diminishes the power of Native actors - even within the 
context of an event where they held the most power-while simultaneously laying a foundation for beliefs that after the late 1800's, Native forms of leadership disappeared. Throughout several of the texts, a sense of doom established by the authors steals agency from Native peoples. The cultural genocide that occurred is justified as a matter of "fate" and as "time [that] ran out" for Native peoples (Pathways, p. 491). Efforts for resistance were futile, according to the authors of $A$ History, who explain that Native peoples "were doomed to defeat" (p. 390). Vision's authors argue "The Native Americans were doomed because they were dependent on buffalo" and "they had no way to sustain their way of life" (p. 403) - phrasing that neglects the complexity of the time, reinforces a dependency perspective of Native peoples (as opposed to adaptive), and focuses on fatalistic views of Native traditions (as opposed to recognition of persistence and resiliency). As a result of "time running out," Native peoples "faced resignation, fatigue, and heartbreak" (Pathways, p. 491). The authors of $A$ History also note this sense of fatalism and excuse the actions of the invaders: "Times were ripe for war" (p. 387).

In a several cases, the textbook authors strive to recognize the efforts of Native social actors in more responsive ways. The authors of Anthem acknowledge the "tremendous victory" at Little Big Horn, although they are quick to note that the victory was "a temporary one" (p. 441). The Americans authors strive to use more active discourse to describe the efforts of Native actors: Instead of refusing to "obey" treaties and policies, Native peoples "resisted the restrictions imposed upon them" (p. 412). Even when outcomes favor the non-Natives, Native peoples maintain some agency: "The Kiowa and Comanche engaged" and "Spotted Tail ... appealed" (Americans, p. 412). 
The Pathways authors' attention to the tendency for the U.S. government to dictate and define leadership structures within Native groups is also of particular note. They explain, 'Federal agents selected 'chiefs' to sign treaties, but the signers often did not represent the majority of their people" (p. 492).

Honoring Native actors demands recognition of the roles they continued to play beyond 1890. The authors of Anthem make the distinction that "Wounded Knee marked the end of the bloody conflict between the army and the Plains Indians" (p. 441), as opposed to suggesting that it signaled the end of Native cultures. This phraseology leaves the door open for other, nonviolent forms of resistance, as well as resistance efforts aimed beyond the army specifically. Given the broader context of Native resistance efforts - especially after the $1960 \mathrm{~s}$ - this wording is more respectful and accurate than that found in several of the other texts. Similarly, the authors of the Americans provide a sidebar discussing the contemporary Nez Perce in a way that emphasizes cultural revitalization: "the Nez Perce are returning" (p. 414). In these isolated cases, the textbook authors recognize that Native cultures did not vanish at Wounded Knee.

\section{Discussion: (Dys)Agency \& Determination}

Even after Indian Agents ceased to exist in official capacities, various positions, policies, and entities extended their "double orientation" legacy. For example, the Bureau of Indian Affairs enforced federal policies, suppressed perceived anti-government threats in reservation communities, and supervised assimilative boarding schools, while claiming to serve and protect Native interests. In 1975, Congress signed the Indian SelfDetermination and Education Assistance Act into law, which confronted the legacy of 
paternalistic dominance and limited forced assimilative schooling. Despite the principles of the Act and more recent efforts to expand social justice, this study demonstrates conscious, subconscious, or dysconscious exclusion or passivation of Native perspectives by some of today's most influential curricular agents, even though many of these historical events can be described in ways that advance accuracy and Indigenous agency.

It appears that little has changed in terms of textbook discourse surrounding Native peoples, despite the continued "warnings" articulated within an extensive body of scholarship and the recent efforts of multicultural and social justice education scholars. Although previous textbook studies have resulted in substantial improvements in terms of representations of Latino and African Americans-likely due to the critical mass of activists from those groups - the same progress has not been documented for Native peoples (Native peoples in the U.S. constitute less than two percent of the total population) (Padgett, 2012).

The findings of this study are consistent with Sanchez's (2007) analysis, which suggested that while the quantity of references to Native histories has increased in recent years, over-simplification of Native experiences has also grown. Given the everexpanding U.S. history narrative, it appears that curricular agents exchange quality for quantity. This tendency to compromise quality conflicts with recent trends in education. Within the Common Core Standards movement launched in 2009, there is a clear call for enhanced critical and historical thinking. Despite this call, the results of this study demonstrate continued reliance on reductionist descriptions, rather than a shift to inclusion of more primary accounts or multiple perspectives. 
At a fundamental level, standards-based reform conflicts with much of the critical Indigenous scholarship. Throughout the late 1800s and well into the 1900s, Indian boarding and day schools in the U.S. mandated assimilative instruction for their students. Such schools prohibited the inclusion of locally relevant culture and language and forced dominant culture content upon Native children. While a national curriculum is potentially problematic when considering this legacy of colonizing and assimilative schooling, it is important to note that the current standards-based reform efforts are different from many of the earlier assimilative initiatives. For example, the $\mathrm{C} 3$ Framework (2013) indicators emphasize "historical inquiry" (p. 45) devoted to interpreting diverse perspectives (p. 47) and "multiple and complex causes and effects" (p. 49).

Although the C3 Framework has been under development for only a couple of years, its precursors - the Common Core Standards for English Language Arts and Literacy in History/Social Studies and other recent standards developed by national organizations - have influenced discussions for several years. For example, Chick (2006) suggests that National History Standards positively influenced both the quantity and quality of representations of women in textbooks. While progress has been made in terms of some historically underrepresented groups, the U.S. history textbooks analyzed in this study demonstrate continued use of colonizing discourse regarding Native peoples, directly conflicting with the goals of these recent standards-based movements.

While the curricular agents usually avoid explaining their decision-making practices altogether, they occasionally strive to justify their choices (only in the teacher's editions of the textbooks) by pointing to external forces seemingly beyond their control. 
The Pathways authors explain that a "lack of documents written by Native Americans" creates a challenge related to the representation of Native histories (Teacher's Edition, p. 493). In the teacher's edition of A History, the authors suggest that historians are "discoverers" and "creators" (pp. T6-T7) who shape, select, and modify historical stories, often relying on U.S. government historical records easily accessible to the public. The "lack of documents" claim does not align with contemporary views of the field of history education, which are informed by an expanding collection of Native source material. Furthermore, recent standards movements have increased attention to the importance of narrative and oral histories - historical genres overwhelmingly excluded from the textbooks analyzed for this study.

Strategies such as exclusion and passivation go beyond presenting an inaccurate or incomplete view of history. When authors, editors, or educators reinforce the colonizing legacy of curricular misrepresentations, they continue to affect various forms of agency for Native peoples today. While Indigenous peoples have maintained their cultural and spiritual agency throughout history, visibility and power-as opposed to exclusion and passivation - must be realized within the dominant culture narrative in order to advance the efforts of decolonization on a widespread scale. This is particularly important given the need for dominant culture "moral agency" in creating and sustaining societal and institutional change (Applebaum, 2004, p. 68).

The study described in this article demonstrates the need for inclusion of Native perspectives throughout the curriculum development and implementation process. Of the five reviewed textbooks, only the Pathways list of reviewers includes a leading Native historian. Without engaging Native scholars, educators, and leaders in the act of 
confronting and challenging colonizing discourse, dominant culture curricular agents continue to exclude Native experiences. Furthermore, Indigenous peoples need to have an active, as opposed to a passive or token, role in the shaping of curriculum materials. When asked about his contribution to the development of the Pathways textbook, Native historian Donald Fixico noted that he did not review the entire book, since publishers usually send outside reviewers limited sections of the text for review (personal communication, December 11, 2009). He also explained that reviewer suggestions are not necessarily addressed in final versions of textbooks. In addition to visibility, historical agency requires an active role in comprehensive decision-making.

\section{Implications: Transforming Agency within Curriculum \& Curriculum Inquiry}

This study demonstrates the need for recognition of the dysconscious racism within the Indian Agent “double orientation” perpetuated by today’s curricular agents. Although the Indian Agent claimed to serve both government and tribes, he most often advanced the goals of economic progress and government over those of the Native communities. Similarly, today's curricular agents continue to shape their discourse to support dominant culture political, economic, and social interests over social justice and historical accuracy. To advocate for Indigenous histories and experiences within the historical narrative, we must become familiar with motivations driving curriculum development, instead of uncritically replicating dysagentic textbooks that fall short of the expectations informed by current policy.

Recent movements center upon a call for increased complexity and critical thinking, but these emerging initiatives are only the beginning: A more complex, multifaceted understanding of various perspectives could promote a "transformation of 
historical consciousness" (Trofanenko, 2008, p. 579). Educators, in particular, emphasize that excluding Native perspectives and experiences from history textbooks damages the integrity of our collective history (Carjuzaa, Jetty, Munson, \& Veltkamp, 2010; Starnes, 2006). Of course, recognizing the value of such a shift and actually igniting the transformation are not one and the same.

To further explore the implications of this study for transforming educational practice, a framework that draws upon the work of critical Indigenous scholars, ethnohistorians, and culturally responsive educators was applied to the results of the discourse analysis. It is important to note that this framework is meant to offer ideas regarding curriculum resources, but that — as the results of this study demonstrate — such resources do not yet exist. Each guideline offers insight into a decolonizing curriculum that could advance Indigenous agency while deconstructing the dysconscious racism driving curricular stagnation.

Curricular agents and respect for Native peoples. To advance agentive representations of Native peoples, the framework contributors note the importance of including both historical and contemporary Native perspectives, accounts, and counternarratives within curriculum resources. This study demonstrates that today's textbook authors include few primary accounts from Native peoples, and - when they do- they most frequently promote viewpoints associated with assimilation and surrender. In several cases, the authors downplay or discredit important Native events, leaders, and places, further diminishing the cultural and historical significance. Most notably, the authors use passive discourse to position Native actors as simple and dependent while distancing them from real "Americans." This stereotypical depiction continues to inform 
views of Native peoples today: In most of the textbooks, traditional ways of knowing and being are presented as though they should not, and cannot, exist in a modern American society.

Fortunately, recent educational trends have the potential to support curriculum design that more effectively honors Native peoples, communities, and traditions. The Common Core, for example, recognizes the power of narrative and counter-narrative, including oral histories, as a bridge between English Language Arts and history education. In addition, the initiative expects learners to gain comfort analyzing a variety of written and spoken accounts, with attention to genre and purpose. As a result of the Common Core and rising textbook costs, some schools have moved away from basing their curriculum on reductionist textbooks, opting instead to use digital archives of primary documents and other online resources (see, for example, the Foundation for the National Archives" "DocsTeach" resource).

In addition to increased attention to existing counter-narratives, there is a need for Native peoples to actively control the design and implementation of classroom resources. During the standardization of No Child Left Behind (NCLB), Indigene-centric reading and math curriculum was virtually non-existent in public schools, due to federal and state-level qualification requirements for curriculum programs. Even when Indigenous curricular agents developed culturally aligned reading curriculum, contracts were awarded to prescriptive programs developed by non-Native agents working for major publishing companies (Toensing, 2006). Unlike NCLB, the Common Core initiative —at least as presently described - allows for extensive flexibility in terms of resource selection. However, as noted on the Common Core Initiative website (2012), publishing 
companies "will develop new resources around these shared standards" (FAQ page). It is important that Native peoples and their allies have a voice in this process, especially given the tendency to tie school funding to curriculum selection.

The State of Montana offers a model for the development and sharing of Indigene-centric curriculum resources, given its Indian Education for All (IEFA) legislation. The State's Office of Public Instruction works with teachers and tribal members to develop lesson plans and other resources that align with the Common Core Standards. For example, a lesson titled “Analyzing Montana Indians' Points of Historic Significance" asks students to view a film sharing Blackfeet perspectives regarding the Lewis and Clark expedition. Following the film, students write a "reaction paper" considering differences between tribal histories and textbook representations, including attention to the ongoing influence of these points of view.

The Common Core initiative allows a percentage of the standards to be modified to meet specific state expectations. In Montana, these modifications often include direct attention to the Native peoples, histories, and cultures of the state, which will potentially encourage educators and other curricular agents to include Native counter-narratives “even where IEFA is not specifically mentioned" (Pearson Common Core In the News Blog, n.d.). In this example, state level policymakers, who have been greatly influenced by Native communities across the state, are using the Common Core as a vehicle to ensure Indigene-centric curriculum for all students. Interestingly, the largest textbook publishing company in the world, Pearson, has noted Montana's response to the Common Core on its website. It is clear that the Common Core and Indigene-centric education 
policy can, at a minimum, gain the attention of the Great Father publishers, which may be a first step in advancing a decolonizing curriculum.

Curricular agents and storytelling. According to the framework contributors, storytelling is often an important means of sharing history and experience among Native peoples. They emphasize that honoring the storytelling tradition extends beyond simply including more stories from Native sources: Curricular agents and students also need to consider the positionality and motivations of those involved throughout the storytelling process. As evidenced by this study, textbook authors rarely note the complexities that shape primary sources, and even more rarely acknowledge the role of historians, authors, and other curricular agents in the creation of story.

A curricular agent's purpose and target audience shapes the way the story is told, especially given the amount of capital power that informs textbook adoption. Today's most popular curricular agents are marketing products for dominant culture groups who make economic decisions for large school districts. As a result, publishers tend to tailor materials to meet utilitarian and nationalistic goals: They eliminate content that advances the "minority" interest in order to meet the majority demand, and — at the same timeundermine the interests of sovereign nations. Since only a few powerful publishers control the major curriculum programs, small publishers, especially those interested in developing curriculum tailored to specific tribal groups, often cannot compete.

As the results of this study demonstrate, textbook authors view their audience as lacking the sophistication needed to interpret complex views of history. They frequently leave issues related to political and economic epistemology unexamined, and, as a result, societal norms and other factors that influence the storying of events and actors are left 
unquestioned and unexplained. While several of the textbooks provide information regarding the importance of recognizing bias as a reader, the authors do not discuss their own strategies for event selection or omission, source qualification, narrative development, or limitations.

In addition to authors, editors, and publishers, teachers have extensive curricular agency. Therefore, how teachers use textbooks affects beliefs about Native peoples, the telling of history, and the importance of counter-narratives. Educators, community members, and policymakers emphasize that teacher use of curriculum is often more important than the curricular story itself. Despite this belief, research regarding pedagogical responses to dysagentic curriculum remains limited. Much of the scholarship relies upon educator self reflection, which potentially fails to address issues related to subconscious or dysconscious bias. Furthermore, research that draws upon Indigenous community member critique of practice is even scarcer. Since over eighty percent of teachers in the U.S. are white, teacher positionality must be carefully problematized within the context of curriculum use.

Curricular agents and Native ways of knowing. Most critically, the framework contributors emphasize the need for curricular agents to acknowledge and value Native cultural, economic, social, and political epistemologies. To meet this goal, they need to include active representations of diverse Native perspectives - not simply those commonly associated with assimilation. Furthermore, these perspectives should be valued at both holistic and discursive levels. In order to genuinely honor Native ways of knowing and shift the balance of power, educators and curriculum developers must confront the tensions between diverse epistemologies. 
This study is itself a manifestation of the epistemological tensions that continue to drive educational efforts today, since it relies upon methodological practices (e.g. discourse analysis) and dissemination techniques (e.g. publication in an academic journal) widely valued by dominant culture academics. If we believe that "the master's tools will never dismantle the master's house" (Lorde, 1984), Indigenous histories should be honored as entities separate from the dominant culture narrative, since discussing or analyzing them within the context of that narrative is to, in a sense, legitimize a hegemonic existence.

However, some Indigenous scholars emphasize that insistence on an separatist Indigenous curriculum or that "non-Indigenous instructors leave the Indigenous pedagogy to Indigenous people" does not directly advance decolonization in practice, especially given the limited numbers of Native peoples currently involved with public education (Kovach, 2013, p. 117). If dominant culture curricular agents terminate their participation in the process of reshaping the historical narrative to include Native perspectives, they avoid claiming responsibility for historical oppression and they ignore the potential for dysconscious racism to continue to shape social and educational practice. Bias_conscious, subconscious, or dysconscious - informs the decisions curricular agents make regarding the inclusion (or exclusion) and role allocation of Native actors. For example, the textbook authors in this study include Native histories minimally, and they discredit Native perspectives regarding the importance of contextualization, the interrelatedness of concepts, and the fluidity of time. By and large, Native histories are positioned within the broader context of White history, without explanation or critique. The textbooks very rarely acknowledge parallel and independent 
views of Native histories. Instead, historical events that engage Native social actors are worth including in the textbooks only if there is interaction with the dominant culture actors. The curricular agents rarely share their strategies for exclusion and role allocation. When they do, they point to a supposed lack of Native source material or to perceived expectations guiding standards movements.

Historically, externally generated curriculum, including standards and textbooks, has avoided questions of power relationships and reinforced colonizing agendas (Anderson, 2012; MacGillivray, Ardell, Curwen, \& Palma, 2004; Sleeter \& Stillman, 2005). In particular, standardized education is reminiscent of assimilative schooling given its efforts to assure all children learn the same content in the same way (Kovach, 2013). However, it is important to recognize the difference between standardized and standards-based education (Rogers, 2008) and to consider ways alternative curriculum, such as counter-narratives, can address the needs of the Indigenous communities (Kovach, 2013).

Given the current attention to the Common Core Standards, it is particularly timely for schools to recognize the potential for standards-based initiatives to value Native ways of knowing within curriculum design. Although the Common Core Standards do not explicitly demand expanded attention to Native experiences, they do emphasize use of primary texts, multiple perspectives, and critical "close reading." Given the call for increased critical and historical thinking in our schools and in our history classrooms in particular (Wineburg, 2001), it is important to engage students themselves in critical curriculum inquiry. 
Curricular agents have the power to support epistemological pluralism by honoring Indigenous counter-narratives more fully, especially within standards-based systems. However, as they work to expand inclusion of diverse perspectives in schools, it will be important for them to recognize the potential for "commodification" of histories and experiences by/for entities not controlled by Native peoples (Smith, 2005, p. 95). Given the complexity of respecting Indigenous epistemologies, care should be taken with the inclusion of Native perspectives and accounts, especially since written documentation alters lived and cultural experience (Wilson, 1997). Both written primary accounts and collective histories can be considered "sacred texts" and demand guidance from tribal leadership (Peacock, 2013, p. 199).

One of the main critiques of culturally responsive education is the tendency for teachers to look for the toolkit that will simplify their work and help them check diversity off the list. To avoid this view, which reinforces reductionist and additive curriculum models, it is important to view the teacher as a life-long learner and to provide space for continued conversations about access to Indigenous knowledges within and across curriculum. Without such space, teachers may uncritically or inappropriately use overly simplistic curriculum, or they may omit Indigenous content altogether. Teachers who elect to avoid teaching about Native histories and experiences neglect the importance of their own "moral agency" (Applebaum, 2004, p. 68) within decolonizing efforts.

Culturally responsive educators, publishers, and authors work with members of Indigenous communities to advance respect for traditional ways of knowing and storysharing. Specifically, collaboration with Native community members, ongoing culturally responsive professional development, cultural "coaching," and teacher reflexivity are 
important efforts for schools and states working to develop and implement decolonizing curriculum. Of course, these efforts do not automatically ensure responsive curriculum: The ideas of individuals may not represent the tribal collective's interests, teachers may not apply what they learn in professional development, cultural mentors may not be able to work with all teachers effectively, and/or teachers may not recognize their own biases within their reflection. While these efforts may not guarantee culturally responsive education, curricular agents ensure a continuation of the colonizing legacy of curriculum in the U.S. if they resist change and simply rely on the existing order of things.

\section{Conclusions: Toward a Decolonizing Curriculum}

Ideally, within a post-colonial context, curriculum would emerge from within the Indigenous community, protect sacred knowledge, and represent Indigenous epistemologies. Indigenous curriculum would exist in a sovereign space-it would not be positioned within dominant culture curricular materials such as textbooks. While these views of Indigenous curriculum may represent our goals as critical educators and scholars, a theory-practice gap precludes immediate realization of the post-colonial ideal. As this study demonstrates, dominant culture interests continue to drive curricular decision-making, especially at the national and state levels.

Research demonstrates that the transformation of agency within curriculum and curriculum inquiry requires three components: (a) critical review of resources, (b) resistance to colonizing curricula, and (c) responsive teaching for social justice (Parkes, 2007; Trofanenko, 2008). The breadth of textbook research demonstrates a commitment to the first of these components, but our attention to the other two has been unclear. Sanchez (2007) suggests that authors and publishers will "come around" and incorporate 
more culturally responsive representations of Native peoples given enough pressure from teachers and textbook adoption committees (p. 317). While both Loewen $(1995,2010)$ and Sanchez (2007) place considerable weight on the power of educators and curriculum selection committees to generate change, their work, and this study, demonstrates the reality that such change has not yet occurred. To this point, there has not been a shift in curricular discourse, in part because we cannot expect a textbook to revise itself. To change the paradigm, critical stakeholders need to confront the human agents behind the misrepresentations and exclusions and emphasize the potentially oppressive motivations driving discursive decision-making.

As Indian Agents justified their corruption and inaction by drawing upon federal policy, today's curricular agents continue to justify their "dysconscious racism” (King, 1991, p. 135) toward Native peoples by criticizing external forces, such as standardsdriven policy or a perceived absence of Native narratives. With the increased attention to content and skills as framed by the Common Core, now is a critical time for collaborative decision-making that confronts individual, societal, and institutional dysconscious racism. Even within the constraints of standards-based reform, curricular agents have the decision-making power and resources to begin decolonizing curriculum, especially if they cultivate authentic collaboration with Native communities.

Collaboration for curricular change extends beyond work at the design stage. Teachers who work with Native peoples are more effective and culturally responsive, even when utilizing materials that contain colonizing representations (Stanton, 2012). Such collaboration, especially if it is long-term and built upon trusting relationships, can help teachers address their own conscious, subconscious, and dysconscious biases. As 
Carjuzaa, Jetty, Munson, and Veltkamp (2010) note, teachers are highly interested in becoming more culturally responsive in terms of teaching about Native cultures and histories, but they often lack the content familiarity needed to effectively confront and resist curricular colonization. School leaders and policymakers can also engage with tribal members and Native students in collaborative curriculum inquiry, especially when selecting materials, reviewing content standards, or planning professional development for teachers. Teacher educators can provide opportunities for teacher candidates to critique curricular representations and implement community-developed curriculum.

Since the goals of standards-based reform and Indigenous self-determination may be fundamentally opposed, it is likely that curricular agents will only engage in change processes if they believe their own interests will be supported. While awareness of these conflicting goals could encourage continued curricular colonization and/or disengagement from the change process by non-Native peoples, it also could generate new, collaborative understandings of a decolonizing curriculum, if stakeholders pressure curricular agents to regard culturally responsive education as a new, essential interest.

Finally, it is important to recognize and build upon the responsive curricular work already taking place. Beyond the IEFA resources emerging in Montana, many examples of Indigene-centric curriculum exist, especially from First Nations and Maori peoples (see, for example, the Full Circle resource from OSSTF/FEESO). In these contexts, an assertion of Indigenous agency within curriculum has shifted attention from "suppression of Indigenous values and experience within sites of dominant discourses ... to an Indigenous counter narrative within education" (Kovach, 2013, p. 113). 


\section{References}

Alexander, H. (June 9, 1926). Indian Agent sense. The Nation, 647-648.

American Textbook Council (2011). Widely adopted history textbooks. Retrieved from http://www.historytextbooks.org/adopted.htm

Anderson, C. B. (2012). Misplaced multiculturalism: Representations of American Indians in U.S. history academic content standards. Curriculum Inquiry, 42(4), 497-509.

Apple, M. W. (1971). The hidden curriculum and the nature of conflict. Interchange, 2(4), 27-40.

Apple, M. W., \& Christian-Smith, L. K. (Eds.) (1991). The politics of the textbook. New York, NY: Routledge.

Applebaum, B. (2004). Social justice education, moral agency, and the subject of resistance. Educational Theory, 54(1), 59-72.

Appleby, J., Brinkley, A., Broussard, A. S., McPherson, J. M., \& Ritchie, D. A. (2010). The American vision. Columbus, $\mathrm{OH}$ : McGraw Hill.

Archibald, J. (2008). Indigenous storywork: Educating the heart, mind, body, and spirit. Vancouver: UBC Press.

Ayers, E. L., Schulzinger, R. D., de la Teja, J. F., \& White, D. G. (2009). American anthem. New York: Holt, Rinehart, and Winston.

Barsh, R. L. (2000). Banishing the spirits: Indian agents and the Pacific Northwest Winter Dance. Journal of the West, 39(3), 54-65.

Bell, D. A. (1980). Brown v. Board of Education and the interest-convergence dilemma. Harvard Law Review, 93(3), 518-533. 
Berger, B. R. (2013). Elouise Cobell: Bringing the United States to account. In T. A. Garrison (Ed.), "Our cause will ultimately triumph": The men and women who preserved and revitalized American Indian sovereignty (forthcoming). Durham, NC: Carolina Academic Press.

Bishop, R. (2005). Freeing ourselves from neocolonial domination in research: A Kaupapa Maori approach to creating knowledge. In N. K. Denzin \& Y. S. Lincoln (Eds.), The Sage handbook of qualitative research ( $3^{\text {rd }}$ ed., pp. 109-138). Thousand Oaks, CA: Sage.

Boorstin, D. J., \& Kelley, B. M. (2007). A History of the United States. Boston: Pearson/Prentice Hall.

Brayboy, B. (2005). Toward a tribal critical race theory in education. The Urban Review, 37(5), 425-446.

C3 Framework for Social Studies State Standards (2013). National Council for the Social Studies: Silver Spring, MD. Retrieved from http://www.socialstudies.org/c3

Carjuzaa, J., Jetty, M., Munson, M. \& Veltkamp, T. (2010). Montana's Indian Education for All: Applying multicultural education theory. Multicultural Perspectives, 12(4), 192-198.

Cary, L. J., \& Mutua, K. (2010). Postcolonial narratives: Discourse and epistemological spaces. Journal of Curriculum Theorizing, 26(2), 62-77.

Castagno, A. E., \& Lee, S. J. (2007). Native mascots and ethnic fraud in higher education: Using Tribal Critical Race Theory and the interest convergence principle as an analytic tool. Equity \& Excellent in Education, 40(1), 3-13. 
Cayton, A., Perry, E. I., Reed, L., \& Winkler, A. M. (2007). America: Pathways to the present. Needham, MA: Prentice Hall.

Chick, K. A. (2006). Gender balance in K-12 American history textbooks. Social Studies Research \& Practice, 1(3), 284-290.

Common Core Standards Initiative (2012). Frequently Asked Questions. Retrieved from: http://www.corestandards.org/resources/frequently-asked-questions

Costo, R., \& Henry, J. (Eds.). (1970). Textbooks and the American Indian. San Francisco: The Indian Historian Press.

Danzer, G. A., Klor de Alva, J. J., Krieger, L. S., Wilson, L. E., \& Woloch, N. (2012). The Americans. Orlando, FL: Holt McDougal.

Deloria, V., Jr. (1988). Custer died for your sins: An Indian manifesto. Norman, OK: University of Oklahoma Press (Original work published 1969).

den Heyer, K. (2003). Between every "now" and "then": A role for the study of historical agency in history and citizenship education. Theory and Research in Social Education, 31(4), 411-434.

den Heyer, K. \& Abbott, L. (2011). Reverberating echoes: Challenging teacher candidates to tell and learn from entwined narrations of Canadian history. Curriculum Inquiry, 41(5), 610-635. doi: 10.1111/j.1467-873X.2011.00567.x Dys- (n.d.). In Merriam-Webster online. Retrieved from http://www.merriamwebster.com/dictionary/dys-

Fairclough, N. (1992). Discourse and social change. Malden, MA: Polity.

Fixico, D. L. (1997). Introduction. In D. L. Fixico (Ed.) Rethinking American Indian history. Albuquerque, NM: University of New Mexico Press. 
Foundation for the National Archives (n.d.). DocsTeach. Retrieved from: http://docsteach.org/

Gay, G. (2004). The importance of multicultural education. In D. J. Flinders \& S. J. Thornton (Eds.), The curriculum studies reader (2nd ed., pp. 315-320). New York, NY: RoutledgeFalmer.

Gee, J. P. (2005). An introduction to discourse analysis: Theory and method. New York, NY: Routledge.

Grande, S. (2008). Red pedagogy: The un-methodology. In N. K. Denzin, Y. S. Lincoln, \& L. T. Smith (Eds.) Handbook of critical and Indigenous methodologies (pp. 233-254). Los Angeles, CA: Sage.

Kincheloe, J. L. (2006). Critical ontology and Indigenous ways of being: Forging a postcolonial curriculum. Curriculum as cultural practice: Postcolonial imaginations. Toronto, Canada: University of Toronto Press. Retrieved from http://www.freireproject.org/critical-pedagogy-and-philosophy

King, J. E. (1991). Dysconscious racism: Ideology, identity, and the miseducation of teachers. Journal of Negro Education, 60(2), 133-146.

Kovach, M. (2013). Treaties, truths, and transgressive pedagogies: Re-Imagining Indigenous presence in the classroom. Socialist Studies, 9(1), 109-127.

Levstik, L. S., \& Barton, K. C. (2010). Doing history: Investigating with children in elementary and middle schools (4th ed.). Mahwah, NJ: Lawrence Erlbaum.

Loewen, J. W. (2010). Teaching what really happened: How to avoid the tyranny of textbooks and get students excited about doing history. New York, NY: Teachers College Press. 
Loewen, J. W. (1995). Lies my teacher told me: Everything your American history textbook got wrong. New York, NY: Simon \& Schuster.

MacGillivray, L., Ardell, A. L., Curwen, M. S., \& Palma, J. (2004). Colonized teachers: Examining the implementation of a scripted reading program. Teaching Education, 15(2), 131-144.

Manitoba Indian Brotherhood (1974). The shocking truth about Indians in textbooks. Winnipeg, Manitoba: Manitoba Indian Brotherhood.

McCoy, R. R. (2004). Chief Joseph, Yellow Wolf, and the creation of Nez Perce history in the Pacific Northwest. New York, NY: Routledge.

Milner, H. R. (2008). Critical Race Theory and interest convergence as analytic tools in teacher education policies and practices. Journal of Teacher Education, 59(4), 332-346.

National Indian Education Association (NIEA) (2005). Preliminary report on No Child Left Behind in Indian country. Washington, D.C.: National Indian Education Association.

National Indian Education Association (NIEA) (2011). Constitution and By-Laws of the National Indian Education Association. Retrieved from http://www.niea.org/About/Constitution-and-Bylaws.aspx

Ngugi Wa Thiong'o (1986). Decolonising the mind: The politics of language in African literature. Portsmouth, NH: Heinemann.

Ontario Secondary School Teachers' Federation (OSSTF)/ Fédération des enseignantesenseignants des écoles secondaires de l'Ontario (FEESO) (2012). Full circle: First Nations, Métis, Inuit ways of knowing. Retrieved from 
http://www.osstf.on.ca/full-circle-first-nations-metis-and-inuit-ways-ofknowing.pdf

Ostler, J. (2004). The Plains Sioux and U.S. colonialism from Lewis and Clark to Wounded Knee. New York: Cambridge University Press.

Padgett, G. (2012). A critical case study of selected United States history textbooks from a Tribal Critical Race Theory perspective. (Doctoral dissertation). Retrieved from University of South Florida Scholar Commons. http://scholarcommons.usf.edu/etd/4381

Parkes, R. J. (2007). Reading history curriculum as postcolonial text: Towards a curricular response to the history wars in Australia and beyond. Curriculum Inquiry, 37(4), 383-400.

Peacock, J. (2013). An account of the Dakota-US war of 1862 as sacred text: Why my Dakota elders value spiritual closure over scholarly “balance.” American Indian Culture and Research Journal, 37(2), 185-206.

Pearson Common Core In the News (n.d.). How Montana is connecting Common Core with Indian Education for All. Retrieved from: http://commoncore.pearsoned.com/index.cfm?locator=PS1n4y\&elementType=ne ws\&elementId $=187361$

Prucha, F. P. (1986). The Great Father: The United States government and the American Indians. Lincoln, NE: University of Nebraska Press.

Reyhner, J., \& Hurtado, D. (2008). Reading First, literacy, and American Indian/Alaska Native students. Journal of American Indian Education, 47(1), 82-95. 
Rogers, C. A. (2008). Confronting Coyote: Culturally responsive pedagogy in an era of standardization. Democracy \& Education, 17(3), 46-50.

Said, E. W. (1994). Culture and imperialism. London: Vintage.

Sanchez, T. R. (2007). The depiction of Native Americans in recent (1991-2004) secondary American history textbooks: How far have we come? Equity \& Excellence in Education, 40(4), 311-320.

Schreiber, D. (2008). “A liberal and paternal spirit”: Indian agents and Native fisheries in Canada. Ethnohistory, 55(1), 87-118.

Scott, D. (2008). Critical essays on major curriculum theorists. New York, NY: Routledge.

Sleeter, C. E., \& Grant, C. A. (2009). Making choices for multicultural education: Five approaches to race, class, and gender (6th Ed.). Hoboken, NJ: Wiley.

Sleeter, C. \& Stillman, J. (2005). Standardizing knowledge in a multicultural society. Curriculum Inquiry, 35(1), 27-46.

Smith, L. T. (1999). Decolonizing methodologies: Research and Indigenous peoples. New York: Zed Books.

Smith, L. T. (2005). On tricky ground: Researching the Native in the age of uncertainty. In N. K. Denzin \& Y. S. Lincoln (Eds.), The Sage handbook of qualitative research (3rd ed., pp. 85-107). Thousand Oaks, CA: Sage.

Stanton, C. R. (2012). Context and community: Resisting curricular colonization in American history courses. In H. Hickman \& B. J. Porfilio (Eds.) The new politics of the textbook: Problematizing the Portrayal of Marginalized Groups in Textbooks (pp. 173-194). Rotterdam, The Netherlands: Sense Publishers. 
Starnes, B. A. (2006). Montana's Indian Education for All: Toward an education worthy of American ideals. Phi Delta Kappan, 88(3), 184-192.

Stenhouse, V. L. (2009). Rethinking Thanksgiving. Rethinking Schools, 24(1), 51-55.

Toensing, G. C. (2006, June 7). Reading First contracts come under scrutiny. Indian Country Today. Retrieved from: http://indiancountrytodaymedianetwork.com/2006/06/07/reading-first-contractscome-under-scrutiny-117777

Trofanenko, B. M. (2008). More than a single best narrative: Collective history and the transformation of historical consciousness. Curriculum Inquiry, 28(5), 579-603.

Tuck, E., \& Fine, M. (2007). Inner angles: A range of ethical responses to Indigenous and decolonizing theories. In N. K. Denzin \& M. D. Giardina (Eds.), Ethical futures in qualitative research (pp. 145-168). Walnut Creek, CA: Left Coast Press.

van Leeuwen, T. (2008). Discourse and practice: New tools for critical discourse analysis. Oxford University Press.

Wilson, A. C. (1997). Power of the spoken word: Native oral traditions in American Indian history. In D. L. Fixico (Ed.), Rethinking American Indian history (pp. 101-116). Albuquerque: University of New Mexico Press.

Wineburg, S. (2001). Historical thinking and other unnatural acts: Charting the future of teaching the past. Philadelphia, PA: Temple University Press. 


\footnotetext{
${ }^{\mathrm{i}}$ Although critical Indigenous scholars note that it is often preferable to use specific tribal names, most curriculum materials continue to collectively refer to Indigenous groups in the geographic U.S. using "Native American" or "American Indian." Given the data sources for this project, tribal names are used only when specific affiliation is known and/or noted within the curriculum resources. In other cases, "Native," "Indian," and "Indigenous" are used interchangeably to emphasize the discursive complexity associated with predominantly non-Native efforts to generalize diverse tribal groups.

${ }^{\text {ii }}$ When possible, scholars should attribute individual contributions to specific individuals and/or distinguish individual contributions from collective or tribal contributions, especially given the legacy of over-generalization across Indian Country. However, using specific names and/or tribal identification can compromise protection of sources, particularly since Native communities are small. For this study, specific individual contributions are identified only if they have been previously identified in earlier publications or if specific tribal members have agreed to such recognition.
} 